\title{
O ensino de Física na sociedade do espetáculo: uma análise da implemen- tação e do conteúdo em propostas curriculares ${ }^{+* 1}$
}

\author{
Renato Marcon Pugliese ${ }^{2}$ \\ Faculdade de Tecnologia de São Paulo (FATEC) - USP \\ João Zanetic ${ }^{3}$ \\ Instituto de Física - USP \\ São Paulo - SP
}

\section{Resumo}

O presente texto retrata uma análise da implementação e do conteúdo didático de física de duas novas "propostas curriculares" para o Ensino Médio que adentraram a rede estadual de educação básica do estado de São Paulo entre os anos de 2007 e 2010. Da parte do Governo do Estado de São Paulo tivemos a proposta curricular "São Paulo faz escola" e da parte do Governo Federal tivemos a distribuição dos livros didáticos de física do PNLEM 2007. A análise foi construída sob a ótica sociológica do pensador francês Guy Debord a partir do conceito de Sociedade do Espetáculo e sob a ótica político-pedagógica do educador Paulo Freire. Este texto pontua as principais ideias e os principais resultados obtidos contidos na dissertação de mestrado defendida em 2011 pelo autor principal. Desta pesquisa foi concluído que parte da implementação e parte do conteúdo didático de física presente nessas novas propostas curriculares segue a lógica do espetáculo, pela qual conteúdos e ações são divulgados como dialógicos, mas concretizados de maneira autoritária.

\footnotetext{
${ }^{+}$Teaching Physics in the Society of the Spectacle: an analysis of the implementation and content in curriculum proposals

* Recebido: janeiro de 2014

Aceito: dezembro de 2014.

${ }^{1}$ Este texto foi produzido a partir dos resultados de uma pesquisa feita entre 2008 e 2011, a qual levou à escrita de uma dissertação de mestrado em ensino de física (PUGLIESE, 2011). Para este artigo foram selecionados aspectos gerais e alguns dos exemplos mais significativos presentes na dissertação como forma de divulgar o trabalho e suscitar a discussão acerca do caráter espetacular (DEBORD, 1997) notado no ensino de física no Brasil.

${ }^{2}$ E-mail: rmpugliese@ig.com.br

3 E-mail: zanetic@if.usp.br
} 
Palavras-chave: Ensino de Física; Sociedade do Espetáculo; Propostas Curriculares.

\begin{abstract}
This study presents an analysis of the implementation and Physics educational content from two new "curriculum proposals" for High School, that were adopted by the Public School System in the state of São Paulo from 2007 to 2010. On the part of the State Government of São Paulo the curricular proposal São Paulo Faz Escola was designed, while the Federal Government distributed Physics textbooks from PNLEM 2007. The analysis is developed from the perspective of the French sociological theorist Guy Debord, based on the concept of "Society of the Spectacle", and from the perspective of the Brazilian politicalpedagogical educator Paulo Freire. This paper points out the main ideas and results emerged from the master's thesis defended in 2011 by the author. This research concludes that part of the implementation and part of the physics educational content in these new curriculum proposals follow the logic of the Spectacle, in which content and actions are publicized as dialogical, although they are implemented authoritatively.
\end{abstract}

Keywords: Physics Teaching; Society of the Spectacle; Curriculum proposals.

\title{
I. Introdução ${ }^{4}$
}

No início de 2008 aconteceram três mudanças significativas em minha vida. As duas primeiras, de cunho mais profissional do que acadêmico, era que eu estava recém-formado em Licenciatura em Física pela Universidade de São Paulo e havia sido aprovado em concurso público para lecionar na rede estadual de educação básica. A terceira mudança, a princípio de cunho mais acadêmico do que profissional, era que eu havia sido aprovado para cursar o mestrado, já citado acima, e que resultou na pesquisa descrita neste texto. Dessa forma, sofri uma transformação dupla de estudante para professor e de graduando para pós-graduando.

Passado o período de férias escolares iniciei meu trabalho como professor efetivo de física na Escola Estadual Professor Oswaldo Catalano, no bairro do Tatuapé, região leste da cidade de São Paulo. Permaneci nessa escola de 2008 a 2010, e nela foi colhido o material utilizado para esta pesquisa.

\footnotetext{
${ }^{4}$ A introdução foi escrita em primeira pessoa do singular, relativa ao autor principal do texto.
} 
Durante os primeiros anos de docência naquela escola, percebi que havia uma ausência significativa de diálogo entre as pessoas participantes do ambiente escolar - professores, alunos, gestores, pais e governo ${ }^{5}$. Neste caso, refiro-me à ausência do diálogo crítico e consciente sobre as questões escolares, o diálogo inteligente, que estuda, propõe e avalia saídas para os problemas, não o diálogo do senso comum, aquele que vem arraigado de preconceitos e de uma ideia equivocada de escola, esta que "não se tem mostrado adequada aos fins educativos proclamados pelas concepções pedagógicas comprometidas com a emancipação cultural do indivíduo e com a construção da sociedade democrática" (PARO, 2011, p. 10).

Há diversos problemas devidos à falta de diálogo e condições inadequadas de trabalho que podemos identificar nas escolas cotidianamente, desde a falta de comunicação e diálogo entre os agentes participantes da instituição escolar, às imposições e regulamentações advindas de outras esferas do poder. Todas estas questões, observadas na prática docente, me motivaram a investigar alguns aspectos sócio-político-pedagógicos do ambiente escolar.

Iniciados os estudos da pós-graduação, durante o primeiro ano cursei duas disciplinas ${ }^{6}$ que, ao lado das reuniões de estudo do grupo de pesquisa ${ }^{7}$, permitiram que fosse escolhido um caminho para a investigação que estava nascendo.

Primeiramente, percebi que deveria direcionar a base fundamental do estudo para componentes sociológicos e educacionais a fim de tentar identificar raízes desses problemas, ora pensando no ensino da física na escola básica, ora nos temas gerais da escola. Desse modo, no decorrer das discussões, concluí que precisava estudar porque a física escolar insiste em parecer tão distante da "física real":

\section{(...) a física ensinada em nossas escolas é essencialmente matemático-operacional, metodologicamente pobre, sem experimentos, sem história interna ou externa e des- ligada da vivência dos alunos e da prática dos cientistas. Por tudo isso, a física en- sinada nas escolas, a física escolar, nasce sob o signo do distanciamento com rela- ção à "fisica real" (ZANETIC, 1989, p. 177).}

Em um breve levantamento bibliográfico das pesquisas em ensino de física que trazem novos projetos e/ou novas propostas curriculares para a escola básica, notei que é significativamente crescente o número de trabalhos desta natureza que propõem projetos com física moderna e contemporânea (KARAM, 2006 e 2007; GUERRA, 2007; SOUSA, 2009; SIQUEIRA, 2008; entre outros), experimentos de baixo custo e a criação de laboratórios didáticos (ROCHA FILHO, 2007; LABURÚ, 2008; DAMASIO, 2007; LUNAZZI, 2009), interdisciplinaridade, história e filosofia da ciência (MEDEIROS, 2006; MARTINS, 2007; PRAXE-

\footnotetext{
${ }^{5}$ A universidade também deveria, a meu ver, entrar nesta lista de participantes do ambiente da escola básica, mas definitivamente está fora dos seus processos cotidianos.

${ }^{6}$ Complementos de Relatividade, Prof. Manoel Robilotta, e A Educação Frente às Transformações na Dinâmica do Capitalismo, Profa. Lúcia E. N. B. Bruno.

${ }^{7}$ Sob orientação do professor João Zanetic.
} 
DES, 2009; BUENO, 2009; SOUZA, 2008), etc. Contudo, notei que o ensino de física na unidade escolar estudada permanecia da forma tradicional, e que provavelmente notaria a mesma realidade em outras escolas.

O que acontece então? Por que há tamanha rejeição dos novos projetos e propostas para o ensino de física pelos participantes do ambiente escolar? Para tratar dessas questões considerei relevante avaliar razões sociais e pedagógicas que poderiam manter esse distanciamento. Dos vários referenciais teóricos estudados e conhecidos na pós-graduação, escolhi estudar essas questões com o auxílio da análise sociológica de Guy Debord (1931-1994) e da pedagogia de Paulo Freire (1921-1997), partindo da hipótese de que parte dos problemas citados presentes no ensino de física se deve à organização político-social da qual participamos e do distanciamento do ideal de escola que concebemos.

\section{A sociedade do espetáculo}

Guy Debord foi um participante ativo do movimento político que teve nas manifestações de maio de 1968 na França seu maior êxito. Da participação nesse movimento, o qual idealizava a criação de situações políticas revolucionárias, Debord publica, em 1968, o livro $A$ sociedade do espetáculo, onde faz uma leitura marxista da organização da sociedade após a $2^{\text {a }}$ guerra mundial e do domínio de comunicação dos meios midiáticos.

De acordo com Debord, a sociedade tinha como passível de valorização e respeito, acima das pessoas comuns, aquelas que se pautavam no ser ou no ter. Ou seja, as figuras como o padre, o professor, o médico ou o curandeiro eram valorizadas e respeitadas socialmente por sua essência, seu ser. Da mesma forma, pessoas com posses, latifundiários, empresários ou reis, eram valorizadas e respeitadas socialmente por seu poder de compra, seu ter (Fig. 1).

Após a ascensão da publicidade e da propaganda, da massificação do rádio e da televisão, do crescimento da economia baseada no consumo da população, principalmente no pós-guerra, a sociedade passa a se organizar em torno da mercadoria, e dessa forma os valores sociais, aquilo tido como digno de ser respeitado e valorizado, passam a corresponder à imagem das pessoas e das coisas que possuem. O ser e o ter são substituídos pelo parecer. A aparência (imagem) passa a reinar como principal questão social (Fig. 2).

\section{III. É a escola espetacular?}

No início do seu texto, Debord afirma que "o espetáculo não é um conjunto de imagens, mas uma relação social entre pessoas, mediada por imagens" (1997, p. 13). Nesse sentido, e sendo a escola um local de relações sociais, investigamos se estas relações sociais apresentam ou não características espetaculares e, considerando a física como cultura (ZANETIC, 1989) e o ensino de física como parte desta cultura, procuramos exemplos dessa característica em materiais didáticos e na organização pedagógica das propostas curriculares atuais. 


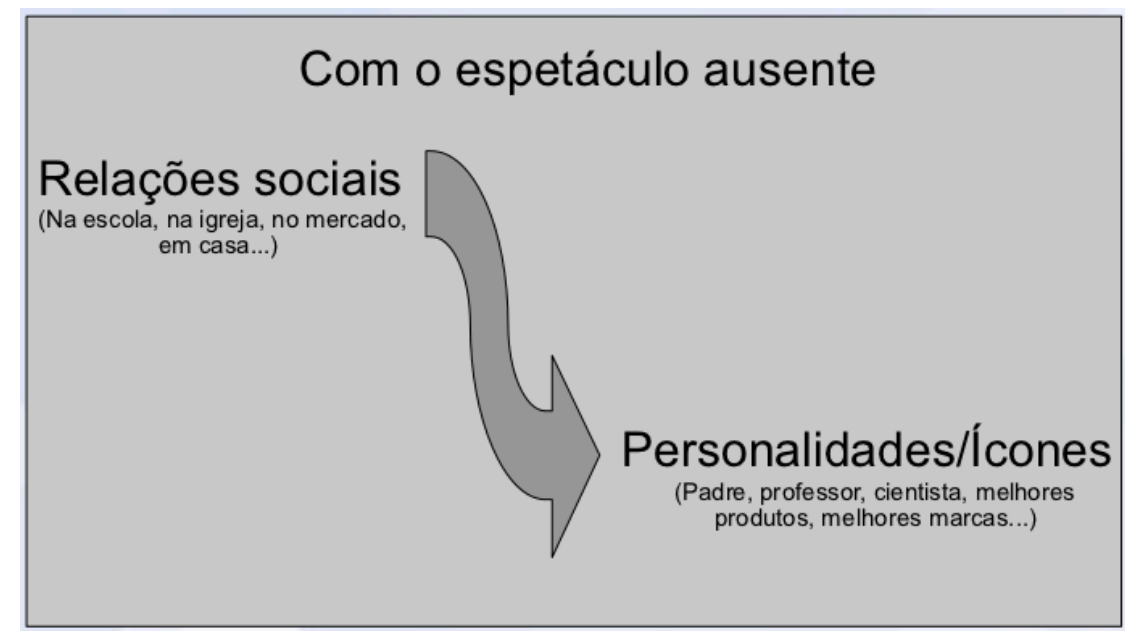

Fig. 1: Representação da organização social com a ausência do espetáculo.

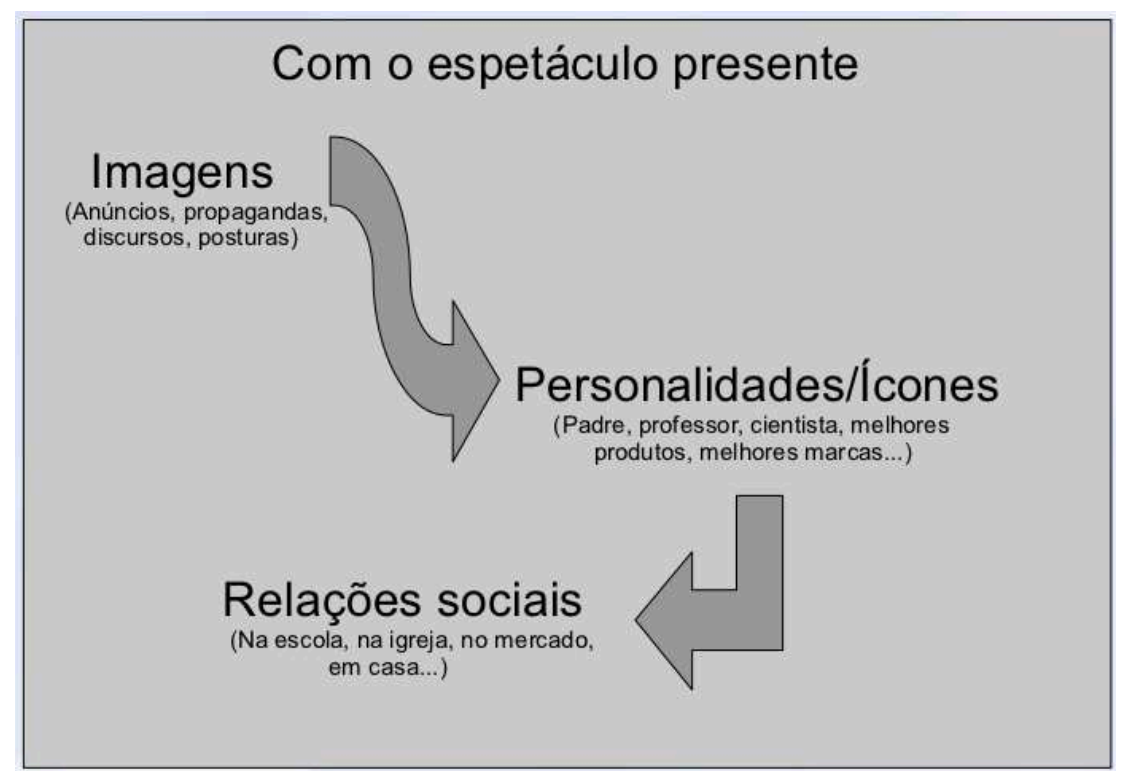

Fig. 2: Representação da organização social com a presença do espetáculo.

Partimos da divisão proposta por FLEURI (2001), para quem as expectativas de postura (do professor, dos alunos, da comunidade escolar) em sala de aula podem ser definidas nos seguintes modelos: autoritário, liberal e libertador. No interior dessa proposta, acrescentamos mais um modelo, o espetacular, para analisar nossos dados. Isto pois partindo do conceito definido por Debord para pensarmos a organização da sociedade atual, fez-se necessária a inclusão de outro modelo, dado que a caracterização do espetáculo (aparência de diálogo com essência de autoritarismo) não se encaixava nos três propostos.

\section{Modelo autoritário}

É comum em debates sobre ensino de física algum autor revisar o modelo de ensino chamado tradicional para utilizá-lo em alguma analogia, comparação ou proposição nova. Em 
física, quando falamos de ensino tradicional facilmente vem a imagem do professor que adentra a sala de aula, expõe um conteúdo físico, geralmente recheado de algoritmos e equações (fórmulas), resolve dezenas de exercícios matemáticos, apresenta listas de exercícios e avalia seus alunos com questões parecidas com as das listas. Nesse modelo geralmente quem escolhe o conteúdo a ser ensinado é o professor, bem como a forma de avaliação, de recuperação, o material didático regular, além de como devem se comportar os alunos e o próprio professor em sala de aula.

Este é o modelo autoritário, no sentido de que todas as decisões que afetam a sala de aula $^{8}$ são tomadas pelo professor de maneira vertical e declarada (explícita). Este modelo valoriza a manutenção da organização social em questão.

\section{Modelo liberal}

Como modelo liberal entendemos o ensino que se pauta pela autonomia dos alunos e dos professores quanto ao conteúdo e à forma do ensino, dentro de uma situação considerada de igual oportunidade a todos os participantes. Neste caso, vale reforçar que a oportunidade de escolha de temas e aulas favorece alunos e professores com maior poder aquisitivo (por exemplo, para adquirir materiais didáticos), maior poder de tempo e transporte (com liberdade para ir e vir de locais onde se dão os estudos), além de favorecer aqueles que dispõem de maior conhecimento da diversidade cultural humana.

Um exemplo deste caso seria a proposta pelo professor de um experimento que deveria ser realizado livremente por grupos de alunos, resultando em um trabalho para apresentação para a classe. Grupos de alunos com maior possibilidade de compra de materiais, maior tempo para pesquisa, mais contatos intelectuais ou melhor formação acadêmica certamente têm mais oportunidades de sucesso.

Este modelo, com sua metodologia liberal, também valoriza a manutenção da organização social, visto que oferece oportunidades consideradas iguais para quem possui condições desiguais.

\section{O modelo espetacular}

O modelo espetacular que acrescentamos vem do conceito de Sociedade do Espetáculo criado por Guy Debord. Neste conceito, a classe dominante, a qual detém o direito de imagem nos principais meios de comunicação (de massa, especialmente), controla o que deve ser visto, o que deve ser comentado e o que deve ser modificado em grandes decisões, porém, sem explicitar esse controle, mas apresentando uma falsa imagem de diálogo, de coletividade ou de sinceridade. $\mathrm{O}$ valor do ter e do ser passa a ser substituído pelo parecer.

\footnotetext{
${ }^{8}$ Ou quase todas as decisões, visto que muitos fatores são decididos pela instituição, como a quantidade de alunos por classe, o horário das aulas, o local das aulas, entre outros.
} 
Neste contexto, a população e os participantes do ambiente escolar assumem o papel de representantes do espetáculo de forma inconsciente, reproduzindo de maneira alienada conceitos, propostas, posturas e comportamentos advindos de uma imposição publicitária que culmina na produção de um senso comum autoritário que sugere explicitamente um diálogo inexistente.

É falseado (divulgado, proclamado, propagandeado) um diálogo entre as partes envolvidas, mas realizado (o processo, a implementação, a escolha) o autoritarismo.

\section{Modelo libertador}

Diferentemente dos modelos anteriores, o modelo libertador, representado principalmente pelos trabalhos do educador Paulo Freire (1996, 2008 e 2009), tem como base de sua organização, em termos de conteúdos, locais, avaliações, etc., a construção coletiva com participação necessária das classes desfavorecidas, oprimidas, da estrutura, da metodologia, dos objetivos e das finalidades dos cursos.

Este modelo considera o homem como produtor das relações sociais, como ente no mundo e com o mundo, e busca humanizar, assim, a proposta de educação.

O equivalente no ensino de física poderia ser citado como trabalhos de investigação científica de fenômenos presentes no cotidiano, produção de sequências didáticas e experimentos em construções coletivas (professor-alunos-escola), exploração aberta (numa analogia com o conceito de Obra Aberta de Umberto Eco) de temas do conhecimento físico, entre outros.

Este seria, entre os quatro modelos descritos, aquele que caminha para desorganizar (no sentido de ir contra a organização vigente) a estrutura atual de ensino.

\section{As novas propostas curriculares}

No período compreendido entre 2008 e 2010, em que foram colhidos os materiais para realização desta pesquisa, duas propostas curriculares foram implementadas na rede estadual paulista de educação básica ${ }^{9}$, a saber: i. São Paulo faz escola - nova proposta curricular do Governo do Estado de São Paulo e; ii. PNLEM 2007 - Programa Nacional do Livro Didático para Ensino Médio do Governo Federal.

Dentre as perguntas que escolhemos para responder acerca destas propostas, destacamos as quatro seguintes:

1. Como se deu a implementação destas propostas? Houve diálogo entre professores, gestores, implementadores, autores dos materiais, estudantes e comunidade?

\footnotetext{
${ }^{9}$ A distribuição de livros didáticos pelo PNLEM, citada adiante, já ocorria há alguns anos. Contudo, apenas no PNLEM de 2007 é que os livros didáticos de Física entraram no programa.
} 
2. Como se deu a construção destes materiais? Houve diálogo entre professores, gestores, implementadores, autores dos materiais, estudantes e comunidade?

3. O conteúdo de física destes materiais dialoga com o conteúdo de física construído pelos físicos? Ou seja, a física escolar está próxima ou distante da física real?

4. Houve espaço para a construção de um projeto político-pedagógico na unidade estudada que contemple estas novas propostas?

Estas questões nortearam a forma como escolhemos o material e como caminhamos em busca das respostas. A seguir faremos uma descrição sucinta destas novas propostas implementadas na rede.

\section{São Paulo faz escola}

De acordo com a Secretaria de Educação do Estado de São Paulo, a implementação desta nova proposta curricular se deu pelo seguinte motivo:

A criação da Lei de Diretrizes e Bases (LDB), que deu autonomia às escolas para que definissem seus próprios projetos pedagógicos, foi um passo importante. Ao longo do tempo, porém, essa tática descentralizada mostrou-se ineficiente (SEE/SP, 2008).

Desse modo, percebemos que a ideia principal do projeto era de centralizar a escolha da metodologia e do conteúdo a ser trabalhado nas escolas, o que inclusive vai de encontro ao que consta na Constituição Federal quando, no inciso III do artigo 206, afirma que o ensino deve atender ao "pluralismo de ideias e concepções pedagógicas".

A proposta foi então construída e implementada em quatro momentos distintos:

$1^{\circ}$. Final de 2007. Construção da nova proposta curricular por especialistas qualificados a pedido da Secretaria de Educação do Estado de São Paulo;

$2^{\circ}$. Início de 2008. Edição especial - São Paulo faz escola: distribuição de uma revista aos professores e de um jornal aos alunos, contendo um plano de recuperação envolvendo todas as disciplinas, o qual continha aulas preparadas e atividades prontas para os primeiros 42 dias de aula (entre 18/02 e 30/03);

$3^{\circ}$. Meados de 2008. Caderno do professor: distribuição, aos professores, dos cadernos bimestrais com conteúdo a ser trabalhado em sala de aula, além de dicas e sugestões de como trabalhar cada conteúdo e como lidar com a classe. No caso de física, cada caderno (bimestral) continha 16 aulas, além de exercícios complementares e propostas de avaliação;

$4^{\circ}$. Início de 2009. Caderno do aluno: começaram a ser distribuídos os cadernos do aluno, os quais continham o mesmo conteúdo dos cadernos do professor, porém com espaço para realização das atividades, exercícios e anotações gerais.

Com exceção dos jornais da edição especial, os quais foram entregues aos alunos e professores no primeiro dia letivo de 2008 (o que gerou um desconforto explícito na equipe 
escolar), os cadernos do professor e do aluno foram entregues sempre com um ou dois meses de atraso (lembrando que eram cadernos bimestrais).

\section{PNLEM 2007}

O Programa Nacional do Livro Didático para Ensino Médio teve seu início em 2004 com a distribuição de livros de Língua Portuguesa e Matemática para as regiões Norte e Nordeste do país. Conforme os anos passaram, o programa cresceu e atingiu todo o território nacional. No caso dos livros de física, o programa teve início nacional em 2007, seguindo o roteiro abaixo:

$1^{\circ}$. Durante o ano de 2007. Triagem e avaliação de livros didáticos de física pelo MEC (Ministério da Educação). Neste momento, seis obras foram consideradas aptas para serem utilizadas nas escolas;

$2^{\circ}$. Meados de 2008. Escolha, pelos professores e equipe escolar, da obra a ser adotada em cada unidade escolar para o ano seguinte, dentre as seis oferecidas pelo MEC;

$3^{\circ}$. Início de 2009. Distribuição da obra escolhida aos alunos para utilização em sala de aula e/ou em casa.

Nota-se então que no ano de 2009 os estudantes e professores de física da rede estadual de educação básica estavam com dois materiais em mãos para utilizarem em sala de aula: os cadernos da nova proposta curricular estadual e os livros distribuídos pelo PNLEM. Além disso, precisamos lembrar, en passant, que a escola pode possuir um projeto político pedagógico próprio e que o professor pode possuir seu material para utilização em sala de aula. $\mathrm{O}$ que possibilita a existência de até quatro propostas diferentes para o ano letivo.

Dado este contexto, e dadas as quatro questões levantadas há pouco, decidimos investigar o caráter (espetacular, autoritário, libertador ou liberal) destas propostas quanto ao conteúdo didático de física e quanto à implementação das mesmas.

Neste artigo, trazemos apenas um caso relacionado ao conteúdo e um caso relacionado à implementação, para exemplificação das ideias.

\section{Quanto ao conteúdo}

Trabalharemos aqui o tema luz e cores, em especial na atividade relacionada à cor de um melão, da proposta estadual São Paulo faz escola, presente no Caderno do Professor: Física - Ensino Médio - 2a série, vol. 4 (SEE/SP, 2009).

A Fig. 3 (figuras 10 e 11 no material explorado) mostra como seria visto um objeto amarelo, neste caso um melão, quando iluminado por luz branca, luz vermelha e luz verde ${ }^{10}$.

\footnotetext{
${ }^{10}$ É importante frisar que as figuras precisam ser vistas em cores. A versão online será publicada de forma colorida, e os leitores da versão impressa poderão acessar as figuras originais na versão digital.
} 


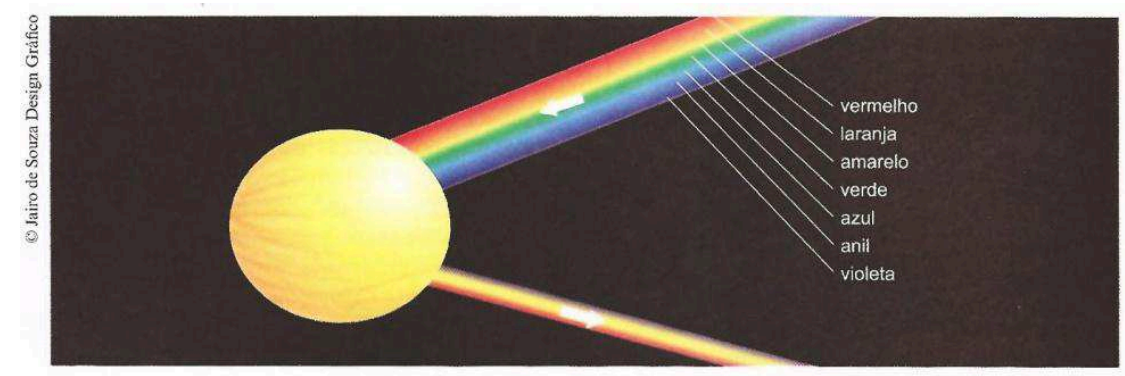

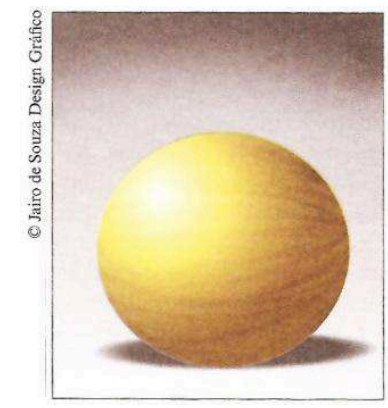

a

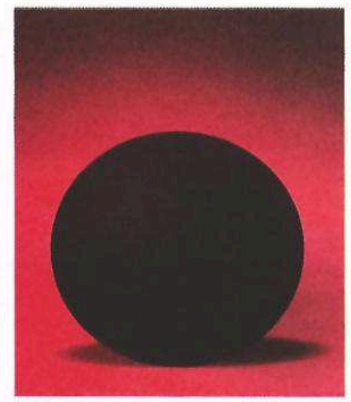

b

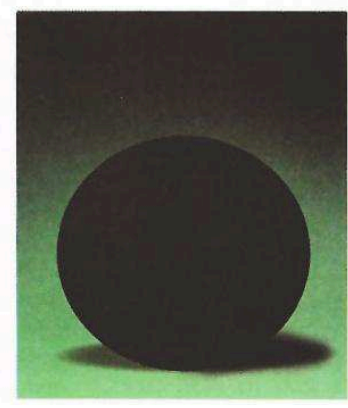

$\mathrm{c}$

Fig. 3: a) Melão iluminado por luz branca; b) Melão iluminado por luz vermelha; c) Melão iluminado por luz verde (SEE/SP, 2009, p. 22).

Percebe-se que houve um trabalho gráfico digital, onde um melão foi desenhado em algum programa de computador, trabalhado com brilho e diferentes projeções de iluminação, com o objetivo de discutir a problemática da cor observada em determinado corpo como função da luz incidente sobre ele.

Algumas questões que podem surgir: Será que no mundo vivido (experimentado) as cores se apresentam desta forma? Será que um melão comprado em um supermercado, ou em uma feira livre, e iluminado por lâmpadas com diferentes cores de luz, proporcionaria este resultado (diálogo homem-mundo)? Numa outra perspectiva, será que a fotografia de um melão com uma câmera digital, levada ao computador e editada com programas para manipulação de imagens (como o Adobe Photoshop@ ou o Gimp@), por meio da sobreposição de filtros de luz, também levaria a estes resultados (diálogo homem-homem)? Ou, por fim, será que no desenvolvimento das teorias acerca das cores há alguma evidência destes resultados (diálogo homem-mundo-homem)?

Utilizamos primeiramente uma câmera de fotografia digital comum, uma lâmpada fluorescente (que produz uma luz mais próxima do branco do que uma lâmpada incandescente, além de ser a mais comum no ambiente escolar), uma sala escura (com as janelas e portas 
vedadas), um melão e alguns filtros coloridos construídos com papel celofane ${ }^{11}$, e foram obtidas as seguintes imagens ${ }^{12}$ :

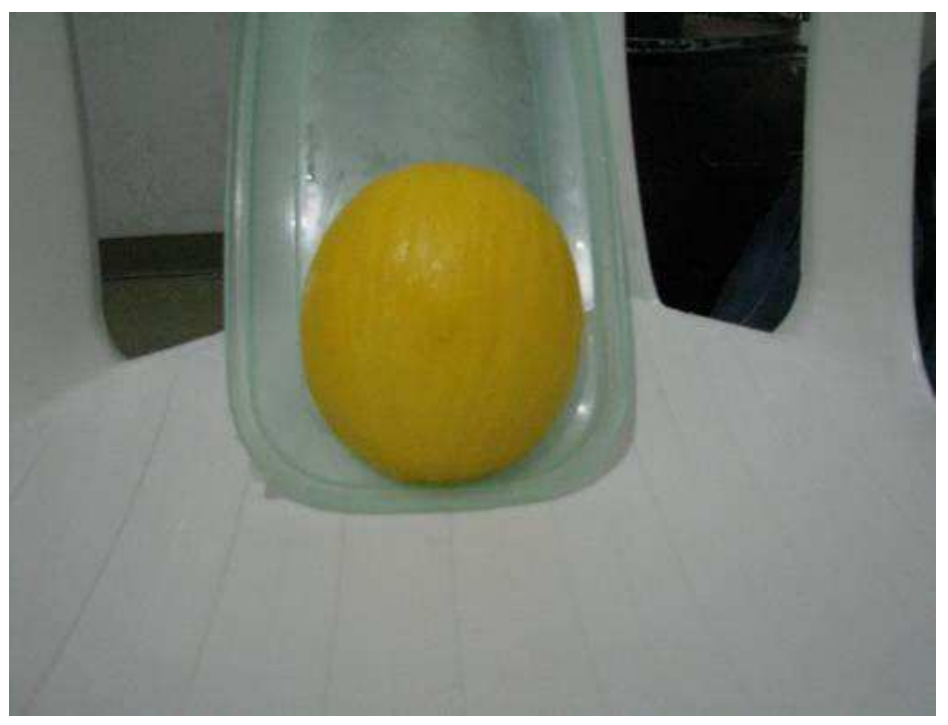

Fig. 4: Melão iluminado com luz branca (lâmpada fluorescente comum).

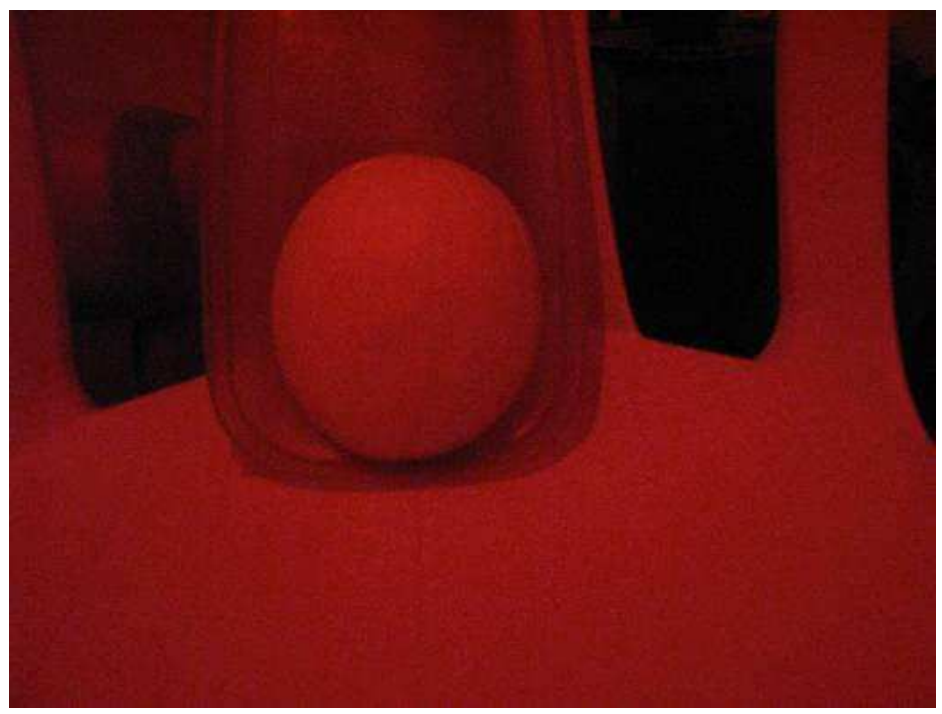

Fig. 5: Melão iluminado com luz vermelha (filtro vermelho em lâmpada fluorescente).

\footnotetext{
${ }^{11}$ A sugestão de utilização do papel celofane como filtro de luz aparece no próprio material didático explorado (p. 11). A utilização de filtros de melhor qualidade, que selecionam melhor as bandas de frequência luminosa que o atravessam, como os feitos à base de Acetato promovem resultados melhores, porém, de igual interpretação.

${ }^{12}$ Imagens coloridas na versão online.
} 


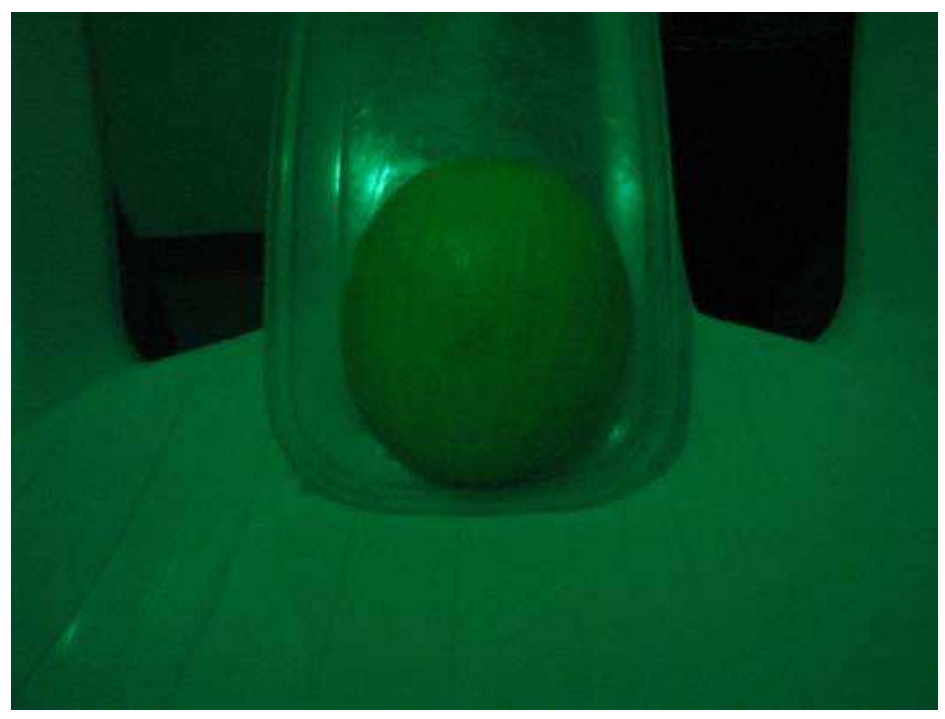

Fig. 6: Melão iluminado com luz verde (filtro verde em lâmpada fluorescente).

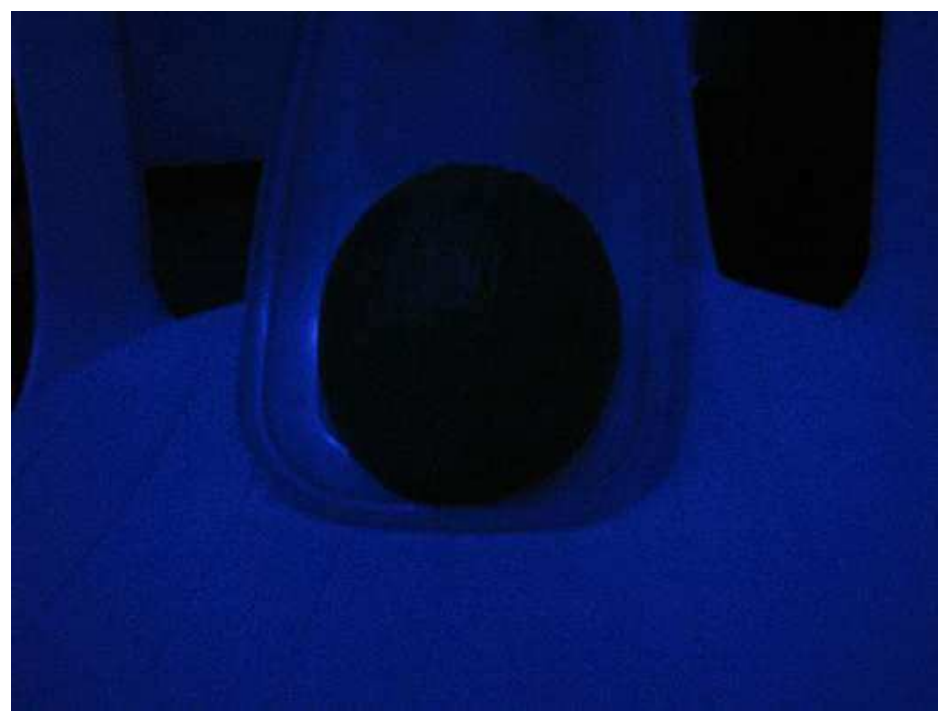

Fig. 7: Melão iluminado com luz azul (filtro azul em lâmpada fluorescente).

Percebemos que há uma diferença significativa com relação às figuras apresentadas no Caderno do Professor quando da aparência colorida do melão iluminado por diferentes tipos de luz. Um fato curioso é que nesta mesma Situação de Aprendizagem do Caderno, há uma demonstração gráfica (também produzida computacionalmente) de como se dá a mistura de cores primárias de luz (verde, azul e vermelha) e quais são suas cores secundárias (amarelo, ciano e magenta). Nesse trecho do texto, é mostrado que a luz verde somada à luz vermelha (sobreposição de ondas) dá a luz amarela, o que justifica o fato de que, se o melão reflete luz amarela quando incidido por luz branca (soma das três cores primárias - Fig. 4), e esta luz amarela é o resultado da soma de verde e vermelho, é possível supor que ele deve refletir também o verde isoladamente e o vermelho isoladamente. Isso foi verificado visualmente e 
registrado quando as fotografias foram tiradas (Fig. 5 e 6), ou seja, quando foi problematizado o diálogo homem-natureza, quando houve diálogo com o mundo. Vale notar que, quando iluminado por luz azul, o objeto se apresenta de cor preta (aproximação), pois não reflete as ondas correspondentes ao azul (Fig. 7) ${ }^{13}$.

O debate sobre as cores primárias de luz, sua absorção e sua reflexão, para a determinação das cores dos objetos vai muito além da descrição acima citada. O padrão de cores RGB (vermelho-verde-azul), que aparece em praticamente todos os materiais didáticos investigados, e que estamos utilizando aqui para fazer as análises, é apenas um padrão possível para seleção e mistura de cores. O fato é que o olho humano identifica alguns padrões de cores, a partir de seus sensores, e o sistema nervoso interpreta como sensação de branco, de azul, de lilás ou qualquer outra cor. Dessa forma, é possível fazer misturas de infinitas maneiras para se produzir o efeito desejado, e o padrão RGB é apenas um dos possíveis padrões, que foi definido em 1931 pela International Comission on Ilumination com base matemática (FERENCE Jr., 1968, p. 201), a fim de facilitar a padronização de produção e interpretação de luz.

Da mesma forma, de acordo com HECHT (2002, p. 168),

não existe um único conjunto de cores primárias, que não tem sequer que ser quase monocromáticas. Uma vez que muitas cores podem ser geradas por mistura de vermelho $(R)$, verde $(G)$ e azul $(B)$, estas primárias são utilizadas com maior frequência.

Além disso, vale lembrar que "a radiação nunca é absolutamente monocromática" (HECHT, 2002, p. 92), e "na prática, sempre analisamos a luz em bandas de frequência, nunca numa única frequência" "14 (DITCHBURN, 1953, p. 99-100). Neste sentido, é possível compreender que quando se trata de determinada frequência de onda, na verdade se trata do pico da banda de frequência analisada.

Retornando agora à discussão sobre a soma das cores (ou sua subtração), HECHT (2002, p. 106) afirma que

um feixe de luz vermelha (com um máximo nos $690 \mathrm{THz}$, por exemplo) sobreposto a outro feixe, este verde (com um máximo nos 540THz), provocará, acredite ou não, uma percepção de luz amarela, mesmo que não haja quaisquer frequências na banda do amarelo.

Isso indica, novamente, que o exemplo gráfico do melão que estudamos está em desacordo com a teoria da luz.

Outra maneira de experimentar essa situação num local onde não fosse possível manter uma sala escura seria no caso de utilizar recursos de computação gráfica. Ou o profes-

\footnotetext{
${ }^{13}$ Aliás, é de extrema beleza observar essas diferentes reflexões visualmente, numa sala escura.

${ }^{14}$ Tradução livre.
} 
sor faria em um computador e mostraria as imagens aos alunos (numa atividade de demonstração) ou, num caso especial onde os alunos tivessem a oportunidade de editarem imagens em algum programa manipulador, poderia ser feita uma atividade problematizante.

Para este texto foi utilizada uma imagem de um melão obtida em páginas de buscas na internet ${ }^{15}$ (Fig. 8):

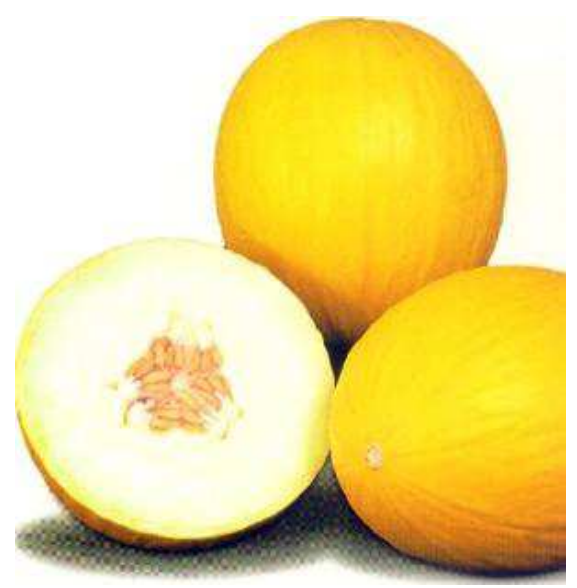

Fig. 8: Imagem de um melão iluminado com luz branca.

A partir desta imagem, utilizando o programa de edição de imagens Gimp ${ }^{16}$, foram inseridos filtros de luz nas cores vermelha, verde e azul. O resultado está nas figuras seguintes ${ }^{17}$ :

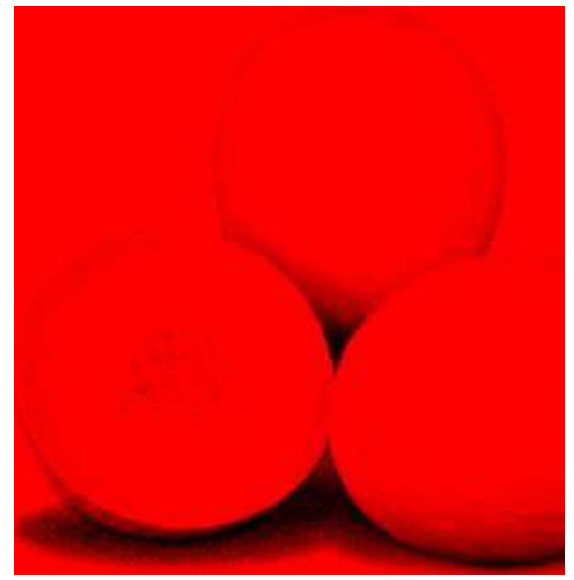

Fig. 9: Imagem sob filtro digital vermelho.

\footnotetext{
${ }^{15}$ A escolha de uma imagem obtida em páginas de busca (como o Google: www.google.com.br) na rede da internet no lugar de utilizarmos uma imagem construída por nós mesmos se deu para demonstrar outra alternativa para o caso da falta de câmera digital ou de objeto da cor desejada.

${ }^{16}$ Gimp - The GNU Image Manipulation Program. Programa de distribuição livre, disponível para Microsoft Windows $\odot$, MAC OS X® ou qualquer distribuição Linux, em <http://www.gimp.org/>. Acesso em: 23 ago. 2013.

${ }^{17}$ Imagens coloridas na versão online.
} 


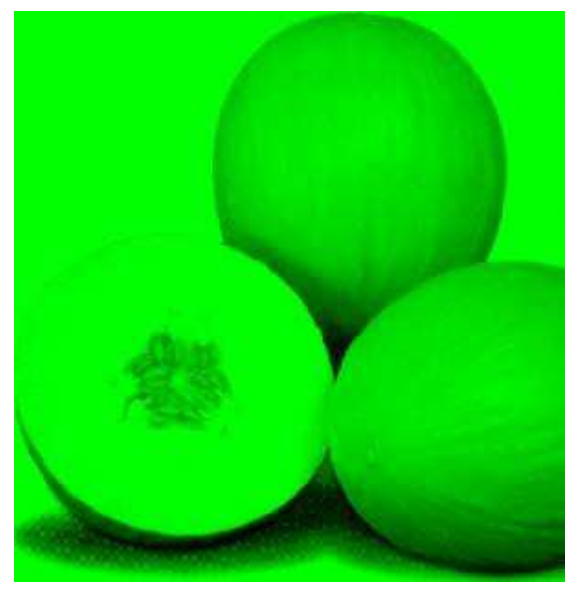

Fig. 10: Imagem sob filtro digital verde.

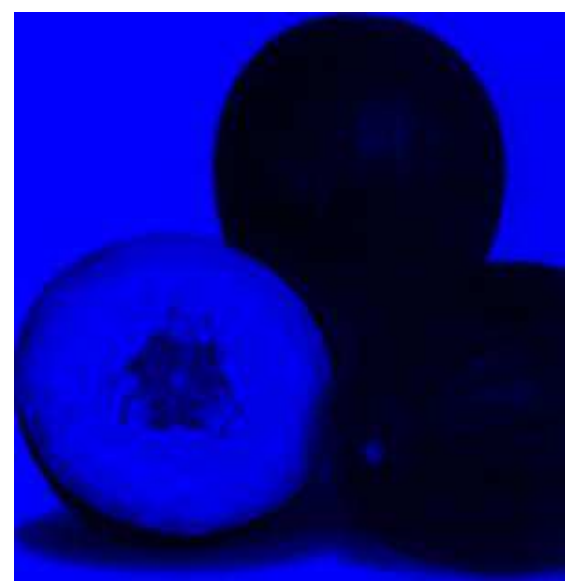

Fig. 11: Imagem sob filtro digital azul.

Verificamos assim que o programa responde de maneira equivalente ao experimento realizado com um melão, filtros, lâmpada e câmera fotográfica reais. O diálogo entre a equipe responsável pela construção do programa, a natureza e o usuário manipulador condiz com o diálogo direto com a natureza ${ }^{18}$, o que também pode ser valorizado.

Ainda uma terceira possibilidade de dialogar de maneira não espetacular, a partir de um experimento mais simples, seria utilizar a imagem de um melão iluminado com luz branca impressa num papel comum e aplicar sobre ele diferentes filtros diretamente.

Nos três exemplos precisaria ser discutido onde está ocorrendo a separação (subtração pela absorção) das cores, se na lâmpada, se nos filtros, se no monitor do computador ou se na chegada/saída do papel.

Este exemplo não trata de autoritarismo escolar, ou da hierarquia entre produtores do material, professores e alunos, mas sim de um espetáculo que cria reproduções falsas de "i-

\footnotetext{
${ }^{18}$ Com uma beleza menor, com relação ao exemplo das fotografias tiradas com o melão real, devido à satisfação da verificação observacional.
} 
magens" teóricas, isto é, reproduz-se uma ideia (como a do RGB, ou das cores puras, monocromáticas) sem o diálogo (entre o homem e a natureza, por exemplo), o que leva a falsas interpretações e conclusões, como a de que podemos produzir cores puras ou a de que o RGB é o único padrão de cores de luz possível.

Em situações dialógicas, quando há o diálogo do homem com o mundo e com outros homens, a teoria física da luz condiz com o experimento (observação). E mesmo em programas de computador, construídos a partir do diálogo com teorias e observações, também podemos verificar coerência. No entanto, inconscientemente podem ser reproduzidas ideias que são falsas, e de maneira autoritária. É o próprio espetáculo.

No entanto, vale reforçar, o espetáculo que aqui se apresenta não pode ser confundido com o autoritarismo escolar, pois este se faz e se apresenta como uma imposição explícita de verdades, escolhas e métodos, enquanto o espetáculo se apresenta como um processo dialógico, de idas e vindas, não verticalizado, mas se faz de maneira autoritária, uma reprodução não adequada de um modelo que não dialoga com o mundo. $\mathrm{O}$ autoritarismo é a negação assumida do diálogo a priori; o espetáculo é a negação falseada, maquiada, do diálogo.

\section{Quanto à implementação}

Tomemos como exemplo a proposta curricular São Paulo faz escola. Neste artigo, apresentamos dados da primeira fase da implementação, entre 2007 e $2008^{19}$.

De acordo com a Secretaria de Educação ${ }^{\mathbf{2 0}}$, durante o ano de 2007 foram definidas algumas metas para a educação paulista, a partir de resultados de avaliações institucionais, como segue abaixo:
A partir dos resultados do SAEB (hoje Prova Brasil), do Enem e de outras avalia- ções realizadas em 2007, o Governo do Estado de São Paulo elaborou 10 metas pa- ra a educação paulista, a serem conquistadas até 2010.
Para isso, propôs uma ação integrada e articulada, cujo objetivo era organizar me- lhor o sistema educacional de São Paulo. A chamada Proposta Curricular criou uma base curricular comum para toda a rede de ensino estadual.
Para elaborar a Proposta Curricular, a Secretaria de Estado da Educação pediu aos professores, coordenadores e diretores que enviassem relatos de boas experiên- cias de aprendizagem na rede pública de ensino ${ }^{21}$.

No início de 2008 os primeiros materiais chegaram nas unidades escolares, além das primeiras informações sobre como estava sendo implementada esta nova proposta curricular. Um dado importante é que na referida escola não havia conhecimento por parte de nenhum

\footnotetext{
${ }^{19}$ Para melhor compreensão, ver (PUGLIESE, 2011).

${ }^{20}<$ http://www.rededosaber.sp.gov.br/portais/Default.aspx?alias=www.rededosaber.sp.gov.br/portais/spfe2009>. Acesso em: 23 ago. 2013.

${ }^{21}$ Grifo nosso.
} 
professor sobre qual era o material, sua forma, como seria dada sua utilização, sobre a obrigatoriedade ou não de seu uso, entre outras informações.

Os professores iniciaram o exercício profissional de 2008, após o recesso e a atribuição das aulas, numa quinta-feira, 14 de fevereiro, sendo convocados para o planejamento escolar nesse dia e no dia seguinte, pois as aulas se iniciariam na segunda-feira, 18.

Aos professores foram apresentados, então, os jornais, que seriam distribuídos para os alunos como parte da nova proposta curricular que estava sendo implementada, bem como a Revista correspondente à sua disciplina. $\mathrm{O}$ recebimento do material foi surpreendente, com desconhecimento total por parte dos professores, o que significa ausência de diálogo entre Governo e Escola, diferentemente da informação transmitida pela Secretaria de Educação (vide citação acima).

As aulas se iniciaram, conforme planejado, na segunda-feira, 18, tendo como material para uso em sala de aula os Jornais do Aluno. Um fato importante é que o material continha as aulas já preparadas, reservadas para todos os dias (desta edição especial), o que levou professores à dúvida quanto à aplicação do planejamento que haviam feito individual ou coletivamente antes das aulas, bem como se poderiam adiar em uma aula o início do uso do material por conta de se fazer uma conversa inicial com os alunos, explicando o uso, a nova Proposta e o que seria estudado, aprendido e problematizado. Afinal, uma prática docente muito comum em cursos oferecidos para crianças, adolescentes e até aos adultos é a de utilizar a primeira aula para dialogar com as turmas, apresentar-se e apresentar o programa do curso, conhecer os estudantes (origem, nomes, comunidades) e, principalmente, o material que haviam acabado de receber (Jornal do Aluno).

No entanto, as aulas estavam programadas (prontas) neste material para começar naquela segunda-feira e acabar no período exato de aplicação da proposta, o que inviabilizaria qualquer possibilidade de diálogo entre os participantes (professores e alunos) daquele curso. Outra questão que esteve presente era sobre a necessidade de concluir as aulas programadas exatamente como estava no material, ou se seria possível ultrapassar a data limite de 30 de março.

Surgiram também problemas de ordem local como, por exemplo, o fato de que na primeira semana de aulas há um dia em que, nesta unidade escolar, tradicionalmente os alunos "veteranos" se dedicam a "recepcionar" os novos alunos, com uma festa, pinturas, gritos de guerra, e outras práticas comuns em muitas escolas. Esta "reserva" por parte dos veteranos já causou um atraso não previsto pelo Governo, e que gerou confusão na escola, pois já não seria possível terminar a aplicação no prazo estabelecido. E aqui cabe uma observação de Paulo Freire sobre uma prática educacional opressora e invasiva que

desrespeitando as potencialidades do ser a que condiciona, a invasão cultural é a penetração que fazem os invasores no contexto cultural dos invadidos, impondo a estes sua visão do mundo, enquanto lhes freiam a criatividade, ao inibirem sua expansão (FREIRE, 2008, p. 173). 
É evidente que, por todos esses motivos, um sistema tão rígido de aulas (autoritário), um sistema praticamente apostilado (no sentido de cursos comumente apostilados, com rigidez na sequência didática) e sem nenhuma possibilidade de flexibilização, não foi completado. Enquanto alguns professores reclamavam que não conseguiam terminar uma aula prevista no Jornal para 50 minutos, e acabavam levando de duas a quatro aulas, outros reclamavam da incoerência da sequência didática das aulas, ou mesmo do material preparado para o $2^{\circ}$ ano ser igual ao do $3^{\circ} \mathrm{ano}^{22}$.

No fim de março, quando acabara o prazo e os Jornais foram recolhidos, começaram a chegar os Cadernos do Professor, distribuídos para que os professores fossem utilizando em aula, ainda sem muitas informações e sem obrigatoriedade, mesmo porque a implementação efetiva, com os Cadernos do Aluno só ocorreria em 2009.

$\mathrm{Na}$ atual (2011) descrição da Secretaria de Educação em sua página na internet, é apresentado o seguinte histórico desse processo:

No começo de 2008, a Secretaria elaborou o Jornal do Aluno para toda a rede estadual paulista. Durante 42 dias, os alunos fizeram uma recuperação pontual em português e matemática que englobou o material e a Revista do Professor, rebatizada posteriormente de Caderno do Professor.

Depois desse período, os cerca de 3,6 milhões de estudantes que participaram do projeto foram avaliados ${ }^{23}$. Os que ainda necessitavam de reforço, continuaram em processo de recuperação no contraturno (nota 16).

Partindo de afirmações como esta diferenciamos a atuação da Secretaria de autoritária ou dialógica para espetacular. A recuperação mencionada não foi realizada como esperado, pelos motivos já levantados, e tampouco os alunos que ainda necessitavam de reforço continuaram em processo de recuperação no contraturno, visto que não havia condições para contratação de professores em turnos extras e menos ainda de novos professores.

Nota-se que a divulgação de uma imagem de diálogo entre Estado, gestores e professores não casa com a implementação concreta da proposta, o que direciona a conclusão para uma prática espetacular (divulgada como dialógica e implementada de forma autoritária), diferentemente de uma prática autoritária (no caso da divulgação de um sistema vertical, que não ocorreu) ou de uma prática libertadora (no caso da implementação de forma dialógica).

Ainda na Linha do Tempo apresentada pela Secretaria da Educação, outra afirmação demonstra claramente o caráter espetacular desta implementação, onde afirma que

\footnotetext{
${ }^{22}$ Muitos alunos, principalmente os terceiranistas, também reclamaram de terem as mesmas aulas que os segundanistas, com um sentimento ora de incapacidade, ora de atraso.

${ }^{23}$ Sobre a avaliação institucional que ocorreu, a fim de identificar melhorias e recuperações na aprendizagem dos alunos, cabe ressaltar que causou apreensão em muitos professores, pois não tinham certeza quanto à obrigatoriedade de insistirem mais na utilização do Jornal do Aluno em sala de aula, e poderiam, por isso, ter prejudicado seus alunos com a ausência de algum conteúdo específico.
} 
constantemente, a Secretaria de Estado da Educação pede uma devolutiva dos professores, gestores e alunos referente aos materiais da Proposta Curricular. Nesta primeira pesquisa sobre o Caderno do Professor, foi possível consultar o corpo docente para aperfeiçoar a Proposta Curricular e revisar o material (nota 16).

Esta prática também não condiz com os fatos ocorridos. Como professor da rede, o autor principal deste texto, em contato permanente com gestores, coordenadores e outros professores da referida escola, não foi solicitado em nenhuma ocasião e não conheceu nenhuma iniciativa deste tipo em todo o período presente na escola, entre 2008 e 2010. Cabe aqui mais uma menção ao desrespeito da Constituição Federal uma vez que no inciso VI, do seu artigo 206, é afirmada a "gestão democrática do ensino público". Observamos mais uma vez que a construção e a implementação desta proposta curricular tem características espetaculares, ou seja, se faz autoritária mas se apresenta como dialógica.

\section{Considerações finais}

No ensino de física, podemos dizer que o espetáculo aparece em implementações de propostas curriculares, em conteúdos de materiais didáticos e, provavelmente, ainda que não discutido neste trabalho, mesmo na postura e no discurso do professor em sala de aula. No primeiro caso, temos implementações de propostas curriculares que, apesar de os implementadores defenderem publicamente o diálogo e a construção coletiva dos processos, elas são construídas, de fato, de forma autoritária, vertical, unilateral e individual.

No caso dos conteúdos de materiais didáticos de física, temos textos que, apesar da assinatura do autor na capa do livro e do discurso na apresentação, facilmente percebemos diversos trechos que estão sendo reproduzidos há décadas de outros materiais, 'teorias' que são transmitidas sem nenhuma relação com teorias físicas concretas, além de exemplos práticos que sequer foram experimentados e realizados na vida real.

Por fim, é provável que no discurso dos professores de física possamos encontrar narrações de teorias e de conceitos científicos que foram apreendidos (seja durante a formação na licenciatura, seja na prática da resolução de exercícios de vestibulares) ao longo do tempo e que não têm quaisquer relações com as teorias físicas e a interpretação física dos fenômenos.

É a falsa concepção de ciência, que se torna real quando realizada em ciclo (discurso-escola-avaliação-discurso). Desse modo,

o espetáculo é a ideologia por excelência, porque expõe e manifesta em sua plenitude a essência de todo sistema ideológico: o empobrecimento, a sujeição e a negação da vida real. O espetáculo é, materialmente, 'a expressão da separação e do afastamento entre o homem e o homem' (DEBORD, 1997, p. 138). 
A implementação dita como dialógica e, no geral, feita de modo autoritário; os conteúdos físicos em livros didáticos publicados como de autoria mas que, no geral, são reproduções; os discursos em apresentações, contracapas e em páginas web. São afirmações não somente autoritárias, mas também, em muitos casos relativos ao conteúdo físico, epistemologicamente falsas. Essas afirmações se tornam reais quando aparecem em questões das avaliações, e resultam em notas que definem a aprovação ou não do aluno. Fecha-se o ciclo: ensino espetacular, avaliação espetacular, notas espetaculares, divulgação espetacular.

\section{Referências}

ALVES, R. Conversas com quem gosta de ensinar. São Paulo: Ed. Cortez, 1993.

BUENO, M. C. F. Os textos originais para ensinar conceitos de mecânica. 2009. Dissertação (Mestrado) - Programa de pós-graduação interunidades em ensino de ciências da USP, São Paulo.

DAMASIO, F.; STEFFANI, M. H. Ensinando física com consciência ecológica e com materiais descartáveis. Revista Brasileira de Ensino de Física, v. 29, n. 4, p. 593-597, 2007.

DEBORD, G. A Sociedade do espetáculo e Comentários sobre a sociedade do espetáculo. Rio de Janeiro: Ed. Contraponto, 1997.

DITCHBURN, R. W. Light. New York: Interscience Publishers, Inc., 1953.

FERENCE Jr., M; LEMON, H. B.; STEPHENSON, R. J. Curso de Física - Ondas (som e luz). São Paulo: Editora Edgard Blücher Ltda e Editora da Universidade de São Paulo, 1968.

FLEURI, R. M. Educar para quê? Contra o autoritarismo da relação pedagógica na escola. São Paulo: Cortez Editora, 2001.

FREIRE, P. Educação como prática da liberdade. Rio de Janeiro: Ed. Paz e Terra, 2009.

FREIRE, P. Pedagogia da autonomia: saberes necessários à prática educativa. Rio de Janeiro: Ed. Paz e Terra, 1996.

FREIRE, P. Pedagogia do oprimido. Rio de Janeiro: Ed. Paz e Terra, 2008.

GUERRA, A.; BRAGA, M.; REIS, J. C. Teoria da relatividade restrita e geral no programa de mecânica do ensino médio: uma possível abordagem. Revista Brasileira de Ensino de Física, v. 29, n. 4, p. 575-583, 2007.

HECHT, E. Óptica. Lisboa: Fundação Calouste Gulbekian, 2002.

KARAM, R. A. S.; SOUZA CRUZ, S. M. S. C. de; COIMBRA, D. Tempo relativístico no início do Ensino Médio. Revista Brasileira de Ensino de Física, v. 28, n. 3, p. 373-386, 2006. 
KARAM, R. A. S.; SOUZA CRUZ, S. M. S. C. de e COIMBRA, D. Relatividades no ensino médio: o debate em sala de aula. Revista Brasileira de Ensino de Física, v. 29, n. 1, p. 105$114,2007$.

LABURÚ, C. E.; MOURA DA SILVA, O. H.; BARROS, M. A. Laboratório caseiro páraraios: um experimento simples e de baixo custo para a eletrostática. Caderno Brasileiro de Ensino de Física, v. 25, n. 1, p. 168-182, abr. 2008.

LUNAZZI, J. J.; MAGALHÃES, D. S. F. Fazendo imagens com um simples elemento difrativo ou refrativo: o axicon. Revista Brasileira de Ensino de Física, v. 31, n. 2, 2501, 2009.

MARTINS, A. F. P. História e filosofia da ciência no ensino: há muitas pedras nesse caminho... Caderno Brasileiro de Ensino de Física, v. 24, n. 1, p. 112-131, abr. 2007.

MEDEIROS, A. A história e a física do fantasma de pepper. Caderno Brasileiro de Ensino de Física, v. 23, n. 3, p. 329-344, dez. 2006.

PARO, V. H. Crítica da estrutura da escola. São Paulo: Ed. Cortez, 2011.

PRAXEDES, G.; PEDUZZI, L. O. Q. Tycho Brahe e Kepler na escola: uma contribuição à inserção de dois artigos em sala de aula. Revista Brasileira de Ensino de Física, v. 31, n. 3, 3601, 2009.

ROCHA FILHO, J. B. DA; SALAMI, M. A.; LIMA, V. M. DO R. Observando a física da não-linearidade em um experimento simples. Caderno Brasileiro de Ensino de Física, v. 24, n. 2, p. 224-232, ago. 2007.

SEE/SP - Secretaria da Educação do Estado de São Paulo. Proposta curricular do Estado de São Paulo - Física - Ensino Médio. IMESP, São Paulo, 2008.

SEE/SP - Secretaria da Educação do Estado de São Paulo. Caderno do professor: física, ensino médio - 2a. Série. Vol. 4. IMESP, São Paulo, 2009.

SIQUEIRA, M. R. DA P. Do visível ao indivisível: uma proposta de física de partículas elementares para o Ensino Médio. 2008. Dissertação (Mestrado) - Programa de pósgraduação interunidades em ensino de ciências da USP, São Paulo.

SOUSA, W. B. DE. Física das Radiações: Uma proposta para o Ensino Médio. 2009. Dissertação (Mestrado) - Programa de pós-graduação interunidades em ensino de ciências da USP, São Paulo.

SOUZA, P. H. Tempo, ciência, história e educação: um diálogo entre a cultura e o perfil epistemológico. 2008a. Dissertação (Mestrado) - Programa de pós-graduação interunidades em ensino de ciências da USP, São Paulo.

ZANETIC, J. Física também é cultura. 1989. Tese (Doutoramento) - Instituto de Física da Universidade de São Paulo, São Paulo. 